\title{
The task complexity and Extraversion: an ERP study
}

Georgiev $\mathrm{S}^{1}$, Philipova $\mathrm{D}^{3}$, Lalova $\mathrm{Y}^{2}$

${ }^{1}$ INB - BAS, 23 Acad. G. Bontchev Str, 1113 Sofia, Bulgaria, stilliyan@mail.bg

${ }^{2}$ INB - BAS, 6 Acad. G. Bontchev Str, 1113 Sofia, Bulgaria, j_lalova@doctor.bg

${ }^{3}$ INB - BAS, 23 Acad. G. Bontchev Str, 1113 Sofia, Bulgaria,dolja@bio.bas.bg

\begin{abstract}
:
Trying to prove the validity of Eysenck's theories for the biological basis of personality many data for the differences between extraverts and introverts were collected. It was obtained, that the ERP differences between extraverts and introverts depend on the intensity and frequency of stimulation, but the papers concerning task difficulty dependence are very limited. The purpose of this work was to investigate how the task complexity affects ERP differences between extraverts and introverts. For testing the extraversion we used Eysenck Personality Questionary (EPQ). We recorded EEG under four equal audio series of pseudo-randomized low and high tones. We changed the level of task complexity by different instructions: 1 - passive listening; 2 - answering with the right index finger to the low tone and the left index finger to the high tone; 3 - counting the low tones; 4 - answering with the right index finger to low tones; We averaged stimulus locked ERP across each series and tones for extraverts and introverts separately. It was evident that the ERP differences between extraverts and introverts depend on the task complexity. We found P2, N2 and P3 latency differences and N1, P2, $\mathrm{N} 2$ and P3 amplitude differences. As whole extraverts showed larger N2 amplitudes and shorter N2 latencies. The differences were more pronounced in the task supposed less complexity and decreased with the increase of task complexity.
\end{abstract}

Keywords: Event-related potentials, EEG, Extravert, Introvert, Personality type;

Introduction:

There are data that interindividual differences and introversion-extraversion dimension can modulate cortical arousal and inhibition. The most popular and investigated theory combining the personality characteristics and functions of the central nervous system is the arousal theory [1]. According to this theory there exists an optimal level of cortical arousal and he ascribes lower cortical arousal compared to optimal for extraverts and higher cortical arousal compared to optimal level for the introverts. There are many arguments and evidences that there is a relationship between personality introversion/extraversion and event-related potentials (ERP).

Event-related potentials (ERPs) are small changes in the ongoing EEG activity, which reflect the patterns of neuronal activity evoked by external stimuli (in different modalities), cognitive processing or preparation and execution of movement. The components of auditory evoked potentials include negative $\mathrm{N} 1$, which peaks at around $100 \mathrm{~ms}$, the consecutive positivity P2, with latency of about 160-200 ms, the negative pick N2 evoked 180 to $325 \mathrm{~ms}$ and the P3 positivity which appear around $300-400 \mathrm{~ms}$ after stimulus presentation. While the $\mathrm{N} 1$ and $\mathrm{P} 2$ have predominant sources in modality-specific areas, the later N2 and P3 may reflect activity of widespread associative cortical networks.

The N1 and P2 components are affected by both exogenous (stimulus intensity and frequency) and endogenous (attentional demands) factors [2]. The N1 becomes more prominent and its latency shortens with increased stimulus intensity [3]. The P2 
increases in amplitude with higher stimulus intensity, but decreases in amplitude when the subject is more attentive [4].

The following N2 and P3 components are thought to represent mainly endogenous activities.

The $\mathrm{N} 2$ negativity is resulting from a deviation in form or context of a prevailing stimulus [5]. It can be elicited by unexpected infrequent stimuli [6], [7], omitted stimuli [8], as well as in classification [9] and target-detection tasks [10], [11]. The N2 amplitude is larger and latency longer when the target is more difficult to discriminate. There exists the assumption [12] that the $\mathrm{N} 2$ component may be related to the effort required to discriminate the target stimulus.

The P3 is usually elicited by detection of a target or an omitted stimulus [13], but may be elicited even in the passive listening condition when multiple equiprobable stimuli are employed [10]. The P3 reflects a number of cognitive processes such as the assessment of stimulus relevance, decision making and perceptual closure at the completion of processing [14]. It is linked to the updating of a cognitive model of the environment within working memory stores [15]. The P3 is affected by a variety of factors, both internal (arousal, emotion, fatigue and age) and external (drugs and ets.) [16].

There are many studies revealing that the ERP differences between extraverts and introverts are manifested only in the certain levels of sensory stimulation. The introverts generate shorter N1 latencies only by low stimulus intensity [17] and P2-N2 amplitude is larger for extraverts in comparison to the introverts, but the differences are significant with greater stimulus intensity [18].

The ERP differences between extraverts and introverts were investigated also in conditions of cognitive tasks. Some authors reported a larger N1 amplitude [19] and larger N1-P2 peak to peak amplitude for introverts [20]. The introverts generated larger $\mathrm{N} 1$ amplitude and shorter P3 latency in comparison with the extraverts when responding at one of two tones [21]. Later it was specified that the extraverts had a longer P3 latency only in condition when the stimulus information is in conflict with requirements for the answer [22]. Some authors reported larger P3 amplitude for extraverts when they reacted on the shorter of two tones [23] and a positive relationship between extraversion and P3 amplitude with the target tones in oddball paradigm [24]. Others [25] didn't find any P3 amplitude differences between extraverts and introverts in oddball paradigm. There are also literature data that opposite results, namely the introverts generated larger P3 amplitudes in comparison to the extraverts in two-tone auditory discrimination task were reported [26].

It was suggested [27] that in tasks with more difficult processing the increasing score of extraversion is related to the increase of $\mathrm{P} 3$ amplitude, while the opposite is right when the tasks paradigm suggest habituation and decreased attention. In an investigation of relationship between the cortical activation and the task complexity using event-related synchronization/desynchronization in the alpha frequency range [28] was found that in easier tasks the introverts are characterized with less cortical activity, but in more difficult tasks they have higher cortical activity in comparison with the extraverts.

The literature data concerning interrelation between ERP component amplitudes and individual characteristics of the persons are contradictory and far from clear. Some of them showed high cortical activation and high amplitudes of ERP components in extraverts, other reported the similar findings in introverts. Even seemingly similar tasks can produce an opposite results. In the same time there are few authors who investigated 
how the extravert-introvert differences depend on task difficulty. The aim of our work was to explore how the differences of stimulus information processing (respectively ERP component differences) between extraverts and introverts are manifested depending on task difficulty.

Methods:

Fifty healthy volunteers ( 23 males and 27 females, mean age $22.2 \pm 2.8$ years, who gave their written informed consent before investigation) participated in the study. All subjects were right-handed [29]. Each person filled the self report Eysenck's Personality Questionnaire (EPQ) adapted for Bulgarian [30]. According to the scores in the extraversion scale the persons were divided in extraverts (more then 12 points of extraversion scale) and introverts (12 and less then 12 points in extraversion scale). The subject was comfortably seated in an ergonomically designed chair within a soundproof, electrically screened chamber monitored by a Canon Video System. The hand and forearm were positioned along the armrests. The index finger was immobilized within a rigid rail attached to a pull-push force transducer: its output signal was proportional to the isometric force produced. An electroencephalogram (bandpass filtered between 0.3 $70 \mathrm{~Hz}$ ) was recorded from $\mathrm{Fz}, \mathrm{Cz}, \mathrm{Pz}, \mathrm{C} 3$ ' and $\mathrm{C} 4$ ', using $\mathrm{Ag} / \mathrm{AgCl}$ "Nihon-Kohden" electrodes with reference to both processi mastoidei, according to the system 10-20. An electrode placed on the forehead served as ground. An oculogram was recorded from $\mathrm{m}$. orbicularis oculi sin. We recorded EEG under four equal audio series in pseudorandomized order of 50 low $(800 \mathrm{~Hz})$ and 50 high $(1000 \mathrm{~Hz})$ tones with an intensity of $60 \mathrm{~dB}$, duration $50 \mathrm{~ms}$ and randomized interstimulus interval between $2.5-3.5 \mathrm{~s}$. We changed the level of task complexity by giving different instructions in the following order: first - passive listening (PL); second - answering with the right index finger to the low tone and the left index finger to the high tone - binary sensory-motor reaction task (BSMT); third - counting the low tones (CLT); fourth - answering with the right index finger only to the low tones (ALT);

ERPs were averaged for each record (Fz, Cz, Pz, C3', C4'), series, tone and personality type separately. We measured also the motor reaction time. A computer program was used to apply Mann-Whitney U-test of statistical data analysis.

We compared the N1, P2, N2, P3 amplitudes and latencies to the extraverts and introverts for each tone and series separately.

Results:

In accordance to the Eysenck's test results we scored 18 persons as introverts (mean score 9,7; standard deviation 3,1) and 32 persons as extraverts (mean score 14,8; standard deviation 1,2). We found significant differences between extraverts and introverts in the amplitudes and latencies of N1, P2, N2 and P3 ERP components.

Latency differences:

N1: We didn't find significant differences between N1 latency of extraverts and introverts in passive listening task.

P2: In the CLT series we found shorter P2 latencies for the extraverts in comparison to introverts. The difference was significant in $\mathrm{Fz}(\mathrm{U}=151 \mathrm{p}<0.01), \mathrm{Cz}(\mathrm{U}=185 \mathrm{p}<0.05)$ and $\mathrm{Pz}(\mathrm{U}=197 \mathrm{p}<0.09)$ for the high (no-target) tone and in $\mathrm{Fz}(\mathrm{U}=175 \mathrm{p}<0.01), \mathrm{Cz}(\mathrm{U}=182$ $\mathrm{p}<0.05), \mathrm{Pz}(\mathrm{U}=167 \mathrm{p}<0.02), \mathrm{C} 3^{\prime}(\mathrm{U}=193 \mathrm{p}<0.07)$ and $\mathrm{C} 4{ }^{\prime}(\mathrm{U}=179 \mathrm{p}<0.04)$ for the low (target) tone. There was no difference between extraverts and introverts for P2 latencies in the ALT and BSMT series. 
High tone
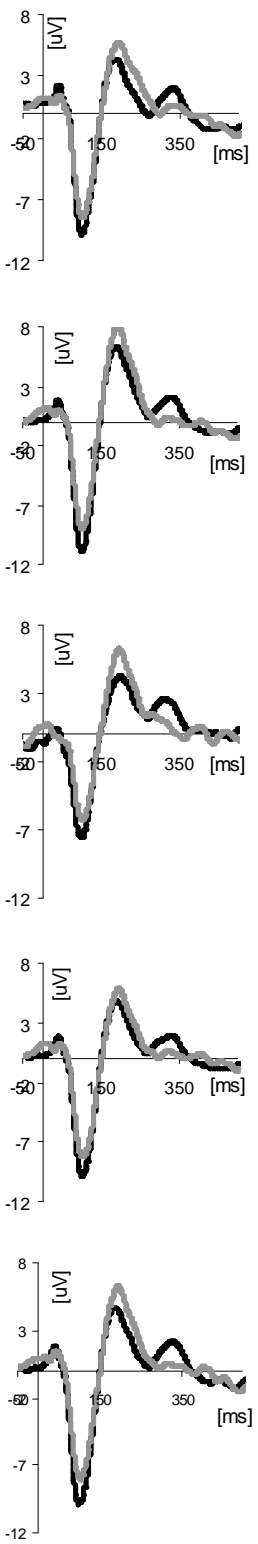

High tone

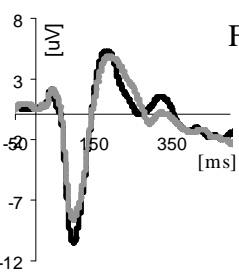

$\mathrm{Fz}$
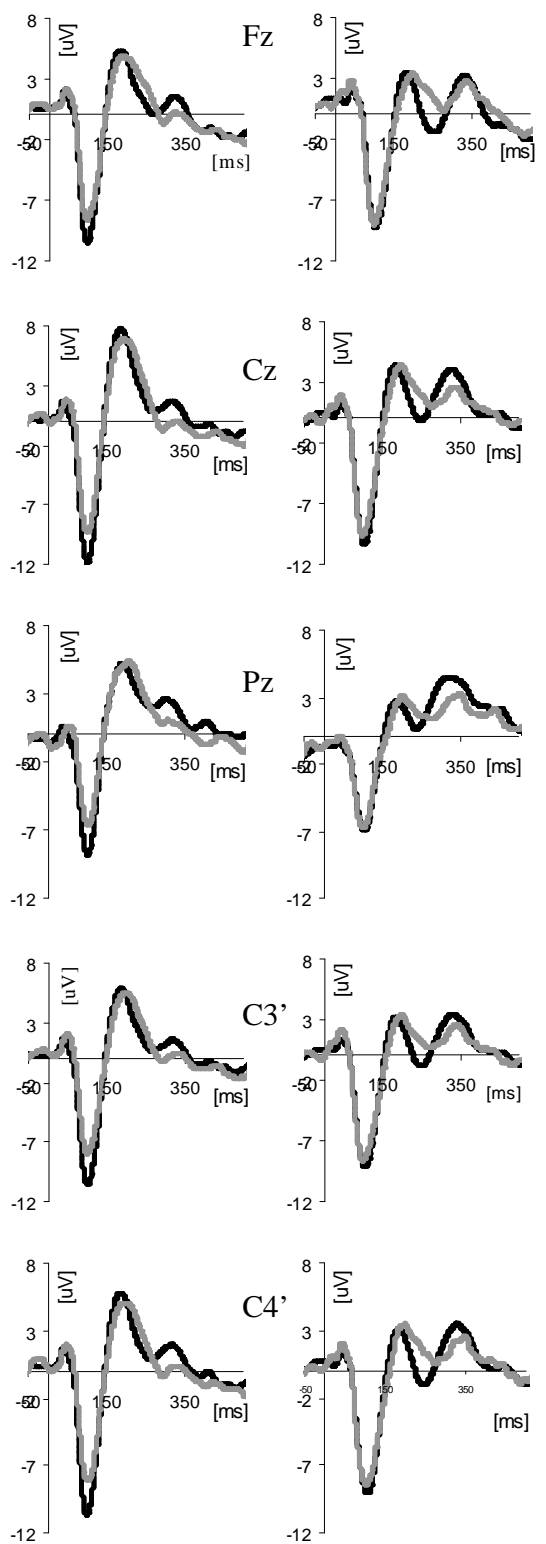

PL
Low tone
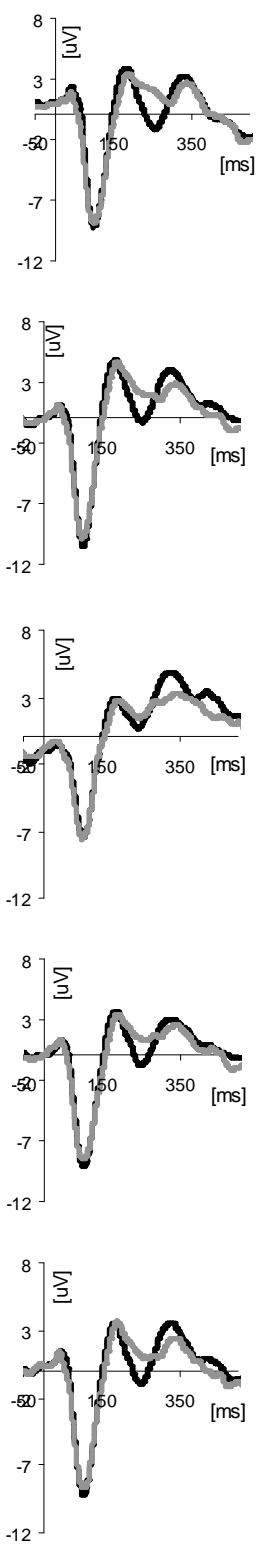

Figure 1. Grand mean of ERP potentials for the extraverts $(-)$ and introverts $(-)$ in passive listening (PL) series and counting low tones (CLT) series. 
High tone
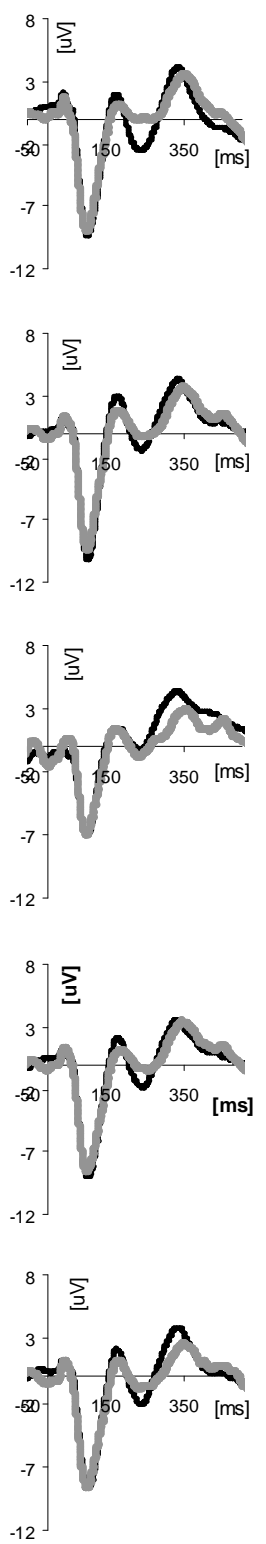

Low tone
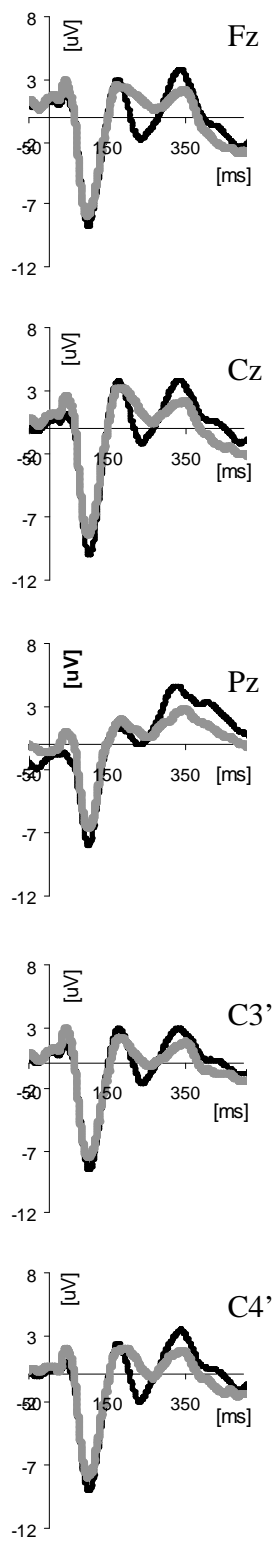

ALT
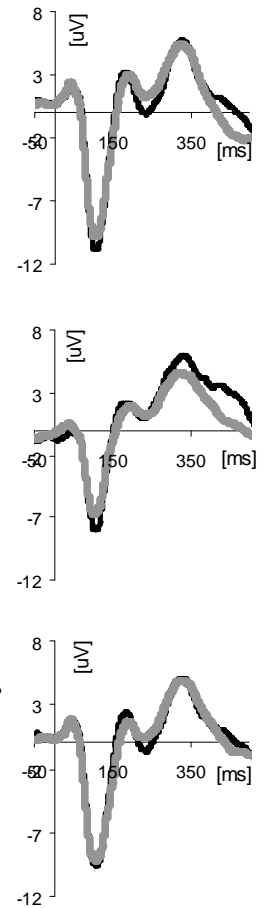

High tone
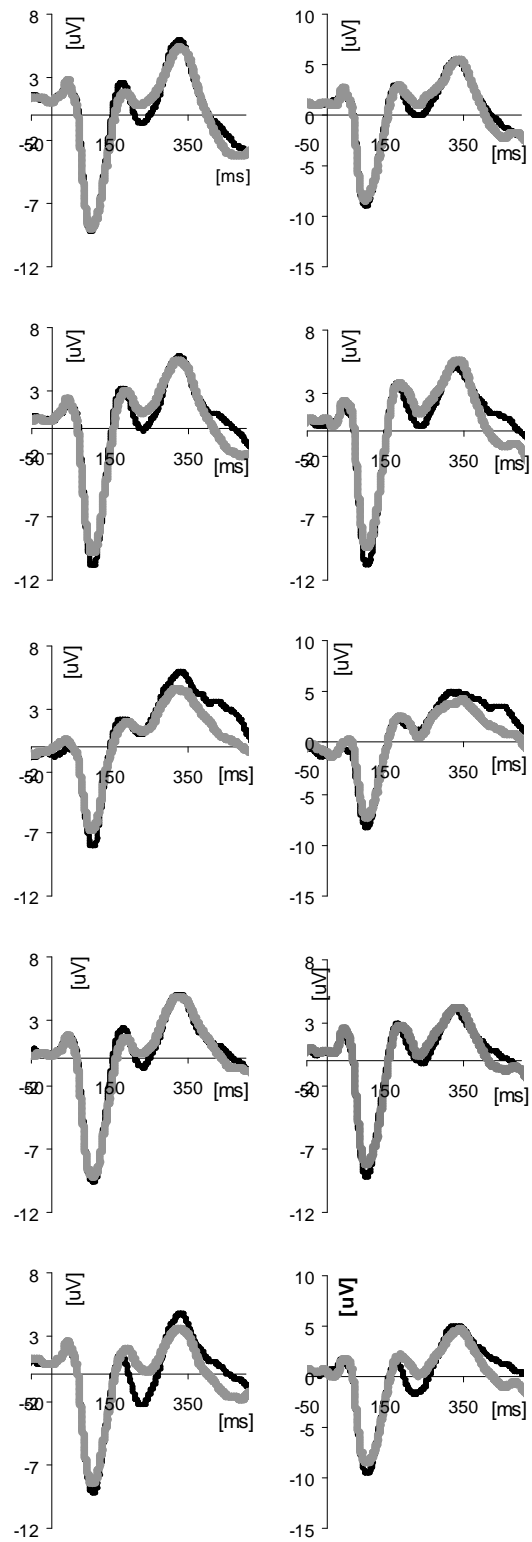

BSMT

Figure 2. Grand mean of ERP potentials for the extraverts (-) and introverts $(-)$ in the answering to the low tone (ALT) series and binary sensory-motor reaction task (BSMT) series. 
N2: In the PL series the extraverts have shorter N2 latencies in comparison to the introverts. This difference was significant in $\mathrm{Fz}(\mathrm{U}=167 \mathrm{p}<0.01), \mathrm{Cz}(\mathrm{U}=188 \mathrm{p}<0.04), \mathrm{Pz}$ $(\mathrm{U}=189 \mathrm{p}<0.04), \mathrm{C}^{\prime}(\mathrm{U}=178 \mathrm{p}<0.03)$ and $\mathrm{C}^{\prime}{ }^{\prime}(\mathrm{U}=178 \mathrm{p}<0.03)$ for the high tone and fronto-central Fz $(U=180$ p <0.03), $\mathrm{Cz}(\mathrm{U}=147 \mathrm{p}<0.001), \mathrm{C} 3$ ' $(\mathrm{U}=200 \mathrm{p}<0.08)$ and $\mathrm{C} 4$ ' location $(\mathrm{U}=162 \mathrm{p}<0.01)$ for the low tone. In the CLT condition the extraverts have shorter N2 latencies compared to the introverts in $\mathrm{Fz}(\mathrm{U}=175 \mathrm{p}<0.03), \mathrm{Cz}(\mathrm{U}=182$ $\mathrm{p}<0.04), \mathrm{Pz}(\mathrm{U}=179 \mathrm{p}<0.04)$ and $\mathrm{C}^{\prime}$ ( $(\mathrm{U}=191 \mathrm{p}<0.07)$ for the high tone and in $\mathrm{Fz}$ $(\mathrm{U}=172 \mathrm{p}<0.03), \mathrm{Cz}(\mathrm{U}=155 \mathrm{p}<0.01), \mathrm{Pz}(\mathrm{U}=186 \mathrm{p}<0.05), \mathrm{C} 3{ }^{\prime}(\mathrm{U}=145 \mathrm{p}<0.01)$ and $\mathrm{C} 4$ ' $(\mathrm{U}=166 \mathrm{p}<0.02)$ for the low tone. In the ALT series the extraverts have shorter $\mathrm{N} 2$ latencies compared to the introverts in $\mathrm{Fz}(\mathrm{U}=181 \mathrm{p}<0.04), \mathrm{Cz}(\mathrm{U}=160 \mathrm{p}<0.01), \mathrm{C} 3$ $(\mathrm{U}=182 \mathrm{p}<0.04)$ and $\mathrm{C} 4{ }^{\prime}(\mathrm{U}=157 \mathrm{p}<0.01)$ for the low tone. In the BSMT series extraverts showed significantly shorter $\mathrm{N} 2$ latencies in $\mathrm{Cz}(\mathrm{U}=183 \mathrm{p}<0.05) \mathrm{Pz}(\mathrm{U}=170$ $\mathrm{p}<0.02) \mathrm{C} 3$ ' $(\mathrm{U}=196 \mathrm{p}<0.08) \mathrm{C} 4$ ' $(\mathrm{U}=168 \mathrm{p}<0.02)$ for the high tone.

P3: In the PL condition the P3 component was shorter for the extraverts in comparison to the introverts in $\mathrm{Fz}(\mathrm{U}=122 \mathrm{p}<0.005), \mathrm{Cz}(\mathrm{U}=145 \mathrm{p}<0.005), \mathrm{Pz}(\mathrm{U}=130 \mathrm{p}<0.005), \mathrm{C} 3$ ' $(\mathrm{U}=156 \mathrm{p}<0.01)$ and $\mathrm{C} 4{ }^{\prime}(\mathrm{U}=146 \mathrm{p}<0.005)$ for the high tone and in $\mathrm{Fz}(\mathrm{U}=179 \mathrm{p}<0.03)$, $\mathrm{Cz}(\mathrm{U}=179 \mathrm{p}<0.03), \mathrm{C} 3{ }^{\prime}(\mathrm{U}=185 \mathrm{p}<0.04)$ and $\mathrm{C} 4$ ' $(\mathrm{U}=169 \mathrm{p}<0.02)$ for the low tone. In the series with motor response for the low tone the extraverts have shorter P3 latency for high tone in C3' $(\mathrm{U}=182 \mathrm{p}<0.04)$ and $\mathrm{C} 4{ }^{\prime}(\mathrm{U}=165 \mathrm{p}<0.02)$ records.

The mean latency of the ERP components for the introverts and extraverts are shown on the tables 1 and 2 .

\begin{tabular}{|c|c|c|c|c|c|c|c|c|c|}
\hline \multirow[t]{2}{*}{ [ms] } & & \multicolumn{2}{|c|}{ N1 } & \multicolumn{2}{|c|}{ P2 } & \multicolumn{2}{|c|}{ N2 } & \multicolumn{2}{|c|}{ P3 } \\
\hline & & Intr. & Extr. & Intr. & Extr. & Intr. & Extr. & Intr. & Extr. \\
\hline \multirow[t]{5}{*}{ PL } & $\mathrm{Fz}$ & 110 & 105 & 195 & 186 & $295 * *$ & $264 * *$ & $379^{* * *}$ & 333 ** \\
\hline & $\mathrm{Cz}$ & 110 & 104 & 195 & 194 & $295 *$ & $268 *$ & 391 *** & 336 ** \\
\hline & $\mathrm{Pz}$ & 113 & 104 & 198 & 199 & $295 *$ & $262 *$ & 388 ** & 326 ** \\
\hline & $\mathrm{C}^{\prime}$ & 111 & 106 & 195 & 192 & $297 *$ & $266 *$ & $377 * *$ & 330 ** \\
\hline & $\mathrm{C}^{\prime}$ & 111 & 107 & 197 & 193 & $292 *$ & $264 *$ & 380 *** & $334 * *$ \\
\hline \multirow[t]{5}{*}{ CLT } & $\mathrm{Fz}$ & 109 & 107 & $202 * *$ & $185 * *$ & $268 *$ & $250 *$ & 340 & 347 \\
\hline & $\mathrm{Cz}$ & 109 & 108 & $200 *$ & $188 *$ & $262 *$ & $246 *$ & 341 & 330 \\
\hline & $\mathrm{Pz}$ & 116 & 110 & $207+$ & $192+$ & $258 *$ & $239 *$ & 348 & 332 \\
\hline & C3' & 109 & 108 & 202 & 192 & $262+$ & $248+$ & 334 & 338 \\
\hline & C4' & 113 & 108 & 201 & 194 & 264 & 255 & 348 & 342 \\
\hline \multirow[t]{5}{*}{$\overline{\mathrm{ALT}}$} & $\mathrm{Fz}$ & 110 & 108 & 183 & 181 & 252 & 239 & 346 & 331 \\
\hline & $\mathrm{Cz}$ & 108 & 109 & 190 & 183 & 253 & 243 & 351 & 341 \\
\hline & $\mathrm{Pz}$ & 107 & 110 & 187 & 191 & 256 & 241 & 350 & 339 \\
\hline & C3' & 110 & 108 & 193 & 187 & 257 & 245 & $354 *$ & $341 *$ \\
\hline & $\mathrm{C}^{\prime}$ & 110 & 109 & 184 & 184 & 252 & 239 & $349 *$ & $332 *$ \\
\hline \multirow[t]{5}{*}{ BSMT } & $\mathrm{Fz}$ & 113 & 110 & 189 & 185 & 254 & 239 & 332 & 338 \\
\hline & $\mathrm{Cz}$ & 113 & 111 & 190 & 190 & $255 *$ & $239 *$ & 334 & 331 \\
\hline & $\mathrm{Pz}$ & 112 & 111 & 194 & 195 & $261 *$ & $239 *$ & 336 & 340 \\
\hline & C3' & 114 & 112 & 191 & 192 & $252+$ & $237+$ & 337 & 334 \\
\hline & C4' & 116 & 113 & 197 & 188 & $260 *$ & $240 *$ & 338 & 335 \\
\hline
\end{tabular}

Table 1. High tone latency differences between extraverts and introverts: $+\mathrm{p}<0.1$; $* \mathrm{p}<0.05 ; * * \mathrm{p}<0.01$; 


\begin{tabular}{|c|c|c|c|c|c|c|c|c|c|}
\hline \multirow[t]{2}{*}{ [ms] } & & \multicolumn{2}{|c|}{ N1 } & \multicolumn{2}{|c|}{$\mathrm{P} 2$} & \multicolumn{2}{|c|}{ N2 } & \multicolumn{2}{|c|}{ P3 } \\
\hline & & Intr. & Extr. & Intr. & Extr. & Intr. & Extr. & Intr. & Extr. \\
\hline \multirow[t]{5}{*}{ PL } & $\mathrm{Fz}$ & 106 & 103 & 196 & 187 & $293 *$ & $264 *$ & $365 *$ & $328 *$ \\
\hline & $\mathrm{Cz}$ & 106 & 104 & 197 & 191 & $290 * *$ & $262 * *$ & $358 *$ & $323 *$ \\
\hline & $\mathrm{Pz}$ & 110 & 107 & 199 & 198 & 278 & 263 & 344 & 322 \\
\hline & C3' & 108 & 105 & 207 & 189 & $291+$ & $266+$ & $354 *$ & $322 *$ \\
\hline & $\mathrm{C}^{\prime \prime}$ & 108 & 104 & 197 & 191 & $292 * *$ & $265 * *$ & $366 *$ & $322 *$ \\
\hline \multirow[t]{5}{*}{ CLT } & $\mathrm{Fz}$ & 106 & 106 & $207 * *$ & $184 * *$ & $271 *$ & $250 *$ & 341 & 331 \\
\hline & $\mathrm{Cz}$ & 108 & 107 & $200 *$ & $187 *$ & $276 * *$ & $251 * *$ & 341 & 339 \\
\hline & $\mathrm{Pz}$ & 107 & 109 & $208 *$ & $189 *$ & $265 *$ & $242 *$ & 342 & 334 \\
\hline & C3' & 108 & 108 & $205+$ & $187+$ & $276 * *$ & $248 * *$ & 346 & 340 \\
\hline & $\mathrm{C}^{\prime}$ & 109 & 108 & $206 *$ & $189 *$ & $275 *$ & $250 *$ & 343 & 338 \\
\hline \multirow[t]{5}{*}{ ALT } & $\mathrm{Fz}$ & 110 & 106 & 193 & 181 & $262 *$ & $243 *$ & 341 & 341 \\
\hline & $\mathrm{Cz}$ & 109 & 107 & 193 & 180 & $265 * *$ & $242 * *$ & 334 & 336 \\
\hline & $\mathrm{Pz}$ & 113 & 107 & 195 & 184 & 253 & 235 & 338 & 345 \\
\hline & C3' & 110 & 108 & 197 & 185 & $261 *$ & $244 *$ & 341 & 338 \\
\hline & $\mathrm{C}^{\prime \prime}$ & 114 & 108 & 196 & 183 & $260 * *$ & $239 * *$ & 340 & 337 \\
\hline \multirow[t]{5}{*}{ BSMT } & $\mathrm{Fz}$ & 109 & 108 & 185 & 190 & 247 & 247 & 342 & 339 \\
\hline & $\mathrm{Cz}$ & 108 & 108 & 190 & 191 & 258 & 244 & 340 & 339 \\
\hline & $\mathrm{Pz}$ & 110 & 108 & 188 & 191 & 248 & 244 & 334 & 340 \\
\hline & C3' & 109 & 108 & 189 & 192 & 258 & 250 & 338 & 336 \\
\hline & $\mathrm{C}^{\prime}$ & 112 & 109 & 191 & 190 & 253 & 246 & 355 & 339 \\
\hline
\end{tabular}

Table 2. Low tone latency differences between extraverts and introverts: $+p<0.1$; $* \mathrm{p}<0.05 ; * * \mathrm{p}<0.01$;

Amplitude differences:

N1: In the PL task the extraverts showed significantly larger N1 amplitude in Fz (U=103 $\mathrm{p}<0.04), \mathrm{Cz}(\mathrm{U}=87 \mathrm{p}<0.02), \mathrm{Pz}(\mathrm{U}=86 \mathrm{p}<0.01), \mathrm{C} 3^{\prime}(\mathrm{U}=91 \mathrm{p}<0.03), \mathrm{C} 4{ }^{\prime} \quad(\mathrm{U}=108$ $\mathrm{p}<0.03)$ records for the high tone and in $\mathrm{Cz}(\mathrm{U}=145 \mathrm{p}<0.08), \mathrm{Pz}(\mathrm{U}=95 \mathrm{p}<0.05), \mathrm{C} 3$ ' $(\mathrm{U}=150 \mathrm{p}<0.02), \mathrm{C} 4{ }^{\prime}(\mathrm{U}=121 \mathrm{p}<0.04)$ records for the low tone.

P2: The P2 component in introverts has larger amplitude in the PL condition. The difference was significant for the $\mathrm{Fz}(\mathrm{U}=122 \mathrm{p}<0.04), \mathrm{Cz}(\mathrm{U}=90 \mathrm{p}<0.01), \mathrm{Pz}(\mathrm{U}=122$ $\mathrm{p}<0.02), \mathrm{C}^{\prime}$ ( $(\mathrm{U}=122 \mathrm{p}<0.04), \mathrm{C} 4$ ' $(\mathrm{U}=122 \mathrm{p}<0.03)$ records for the high tone. There was no difference between extraverts and introverts in P2 amplitudes in ALT and BSMT series.

N2: The N2 amplitude was larger for the extraverts in comparison to the introverts in the PL series. The difference was significant for the high tone in $\mathrm{Cz}(\mathrm{U}=156 \mathrm{p}<0.01), \mathrm{C} 3$ ' $(\mathrm{U}=183 \mathrm{p}<0.06)$ and $\mathrm{C}^{\prime}$ ' $(\mathrm{U}=159 \mathrm{p}<0.02)$ records. In the CLT series the extraverts showed larger $\mathrm{N} 2$ amplitude in $\mathrm{Fz}(\mathrm{U}=127 \mathrm{p}<0.02), \mathrm{C} 3{ }^{\prime}(\mathrm{U}=147 \mathrm{p}<0.07)$ and $\mathrm{C} 4$ ' $(\mathrm{U}=107 \mathrm{p}<0.005)$ for the high tone and $\mathrm{Fz}(\mathrm{U}=163 \mathrm{p}<0.08), \mathrm{Cz}(\mathrm{U}=166 \mathrm{p}<0.09), \mathrm{C} 3$ ' $(\mathrm{U}=129 \mathrm{p}<0.01)$ and $\mathrm{C} 4{ }^{\prime}(\mathrm{U}=165 \mathrm{p}<0.08)$ for the low tone. The extraverts have larger $\mathrm{N} 2$ amplitude in $\mathrm{Fz}(\mathrm{U}=139 \mathrm{p}<0.01)$ for the high tone in the ALT condition.

P3: In the PL task 75 percent of the extraverts and 33 percent of the introverts generated the P3 component. So the extraverts showed larger P3 amplitudes compared to the introverts in $\mathrm{Fz}(\mathrm{U}=186 \mathrm{p}<0.07), \mathrm{Cz}(\mathrm{U}=178 \mathrm{p}<0.05), \mathrm{Pz}(\mathrm{U}=124 \mathrm{p}<0.005)$ and $\mathrm{C} 3$ ' $(\mathrm{U}=148 \mathrm{p}<0.01)$ for the high tone and in $\mathrm{Fz}(\mathrm{U}=173 \mathrm{p}<0.04)$ for the low tone. In the CLT series the extroverts have larger $\mathrm{P} 3$ amplitude in $\mathrm{Pz}(\mathrm{U}=153 \mathrm{p}<0.05)$ for the high tone and $\mathrm{Pz}(\mathrm{U}=153 \mathrm{p}<0.05)$ for the low tone. In the series with motor response for the low tone extraverts had larger $\mathrm{P} 3$ amplitude compared to introverts in $\mathrm{Cz}(\mathrm{U}=148 \mathrm{p}<0.02)$, 
Proc. II South East European Doctoral Students Conference, 2007

\begin{tabular}{|c|c|c|c|c|c|c|c|c|c|}
\hline \multirow[t]{2}{*}[\mathrm{uV}]{} & & \multicolumn{2}{|c|}{ N1 } & \multicolumn{2}{|c|}{ P2 } & \multicolumn{2}{|c|}{$\mathrm{N} 2$} & \multicolumn{2}{|c|}{ P3 } \\
\hline & & Intr. & Extr. & Intr. & Extr. & Intr. & Extr. & Intr. & Extr. \\
\hline \multirow[t]{5}{*}{ PL } & $\mathrm{Fz}$ & $-9,3 *$ & $-11,7 *$ & $7,6 *$ & $5,0 *$ & $-2,5$ & $-1,4$ & $2,3+$ & $3,6+$ \\
\hline & $\mathrm{Cz}$ & $-9,2 *$ & $-12,7 *$ & $10,4 * *$ & $6,5^{* * *}$ & $-2,7 * *$ & $-0,6 * *$ & $2,3 *$ & $3,7 *$ \\
\hline & $\mathrm{Pz}$ & $-6,7 * *$ & $-9,8^{* * *}$ & $8,2 *$ & $5,2 *$ & $-1,5$ & $-0,3$ & $2,7 * *$ & $4,4 * *$ \\
\hline & $\mathrm{C}^{\prime}$ & $-8,6^{*}$ & $-11,5^{*}$ & $7,8^{*}$ & $5,2 *$ & $-2,1+$ & $-0,6+$ & $2,1 * *$ & $3,6^{* * *}$ \\
\hline & C4' & $-8,8^{*}$ & $-11,5^{*}$ & $8,2 *$ & $5,5 *$ & $-2,4 *$ & $-0,9 *$ & 2,4 & 3,4 \\
\hline \multirow[t]{5}{*}{ CLT } & $\mathrm{Fz}$ & $-11,1$ & $-10,5$ & 2,2 & 3,1 & $-2,6 *$ & $-4,8 *$ & 6,2 & 5,2 \\
\hline & $\mathrm{Cz}$ & $-11,5$ & $-11,2$ & 3,5 & 4,1 & $-3,0$ & $-3,1$ & 5,6 & 5,5 \\
\hline & $\mathrm{Pz}$ & $\begin{array}{l}-8,6 \\
\end{array}$ & $\begin{array}{l}-8,2 \\
\end{array}$ & 2,9 & 3,2 & $-2,9$ & $-1,7$ & $4,9 * *$ & $6,0 * *$ \\
\hline & C3' & $-10,5$ & $-9,9$ & 2,3 & 3,2 & $-2,7+$ & $-3,1+$ & 5,0 & 4,8 \\
\hline & C4' & $-10,7$ & $-9,8$ & 2,3 & 3,2 & $-3,0$ *** & $-3,7 * *$ & 4,7 & 5,1 \\
\hline \multirow[t]{5}{*}{ ALT } & $\mathrm{Fz}$ & $-10,2$ & $-11,2$ & 5,7 & 4,0 & $-1,0$ *** & $-3,1 * *$ & 4,8 & 4,6 \\
\hline & $\mathrm{Cz}$ & $-11,0$ & $-11,8$ & 7,0 & 5,0 & $-0,3$ & $\begin{array}{l}-1,7 \\
\end{array}$ & 4,7 & 5,5 \\
\hline & $\mathrm{Pz}$ & $-8,1$ & $-8,1$ & 5,6 & 3,9 & $-0,7$ & $\begin{array}{l}-0,9 \\
\end{array}$ & 4,8 & 6,3 \\
\hline & C3' & $-9,7$ & $-10,7$ & 5,8 & 3,9 & $-0,6$ & $-2,3$ & 4,3 & 4,7 \\
\hline & C4' & $\begin{array}{l}-9,8 \\
\end{array}$ & $-10,5$ & 5,8 & 3,9 & $-0,6$ & $-2,5$ & 4,2 & 4,6 \\
\hline \multirow[t]{5}{*}{ BSMT } & $\mathrm{Fz}$ & $-12,4$ & $-10,2$ & 4,0 & 3,9 & $-0,9$ & $-2,4$ & 7,0 & 7,3 \\
\hline & $\mathrm{Cz}$ & $-12,8$ & $-11,7$ & 5,6 & 4,9 & $-0,5$ & $-1,4$ & 6,9 & 7,4 \\
\hline & $\mathrm{Pz}$ & $-8,9$ & $-8,9$ & 5,2 & 4,0 & $-0,6$ & $-0,6$ & 6,3 & 7,6 \\
\hline & C3' & $-11,8$ & $-10,6$ & 4,0 & 3,7 & $-1,0$ & $-2,0$ & 6,6 & 6,5 \\
\hline & $\mathrm{C}^{\prime}$ & $-11,0$ & $-10,2$ & 4,6 & 3,7 & $-1,2$ & $-2,0$ & 5,4 & 6,0 \\
\hline
\end{tabular}

Table 3. High tone amplitude differences between extraverts and introverts: $+p<0.1$;

$* \mathrm{p}<0.05 ; * * \mathrm{p}<0.01$;

\begin{tabular}{|c|c|c|c|c|c|c|c|c|c|}
\hline \multirow[t]{2}{*}[\mathrm{uV}]{} & & \multicolumn{2}{|c|}{ N1 } & \multicolumn{2}{|c|}{$\mathrm{P} 2$} & \multicolumn{2}{|c|}{$\mathrm{N} 2$} & \multicolumn{2}{|c|}{ P3 } \\
\hline & & Intr. & Extr. & Intr. & Extr. & Intr. & Extr. & Intr. & Extr. \\
\hline \multirow[t]{5}{*}{ PL } & $\mathrm{Fz}$ & $-10,0$ & $-12,3$ & 6,8 & 6,4 & $-2,5+$ & $-1,7+$ & $1,4 *$ & $3,3 *$ \\
\hline & $\mathrm{Cz}$ & $-10,7+$ & $-13,1+$ & 9,3 & 8,9 & $-1,6+$ & $-1,0_{+}$ & 2,6 & 3,6 \\
\hline & $\mathrm{Pz}$ & $-7,3 *$ & $-10,6^{*}$ & 7,4 & 6,8 & $-0,2$ & 0,6 & 3,6 & 4,0 \\
\hline & C3' & $-9,3 *$ & $-12,2 *$ & 6,7 & 6,9 & $-1,0 * *$ & $-1,0 * *$ & 2,5 & 3,2 \\
\hline & C4' & $-9,4 *$ & $-11,9 *$ & 7,2 & 7,0 & $-1,3+$ & $-0,8+$ & 2,4 & 3,4 \\
\hline \multirow[t]{5}{*}{ CLT } & $\mathrm{Fz}$ & $-10,8$ & $-10,6$ & 5,0 & 5,0 & $-1,1$ & $-2,5$ & 4,6 & 4,8 \\
\hline & $\mathrm{Cz}$ & $-11,6$ & $-11,6$ & 6,4 & 5,7 & $-0,5$ & $-1,8$ & 4,7 & 5,2 \\
\hline & $\mathrm{Pz}$ & $\begin{array}{l}-8,9 \\
\end{array}$ & $\begin{array}{l}-8,7 \\
\end{array}$ & 4,7 & 3,7 & $-0,5$ & $-1,0$ & $5,0^{* * *}$ & $6,5^{* * *}$ \\
\hline & C3' & $-9,9$ & $-10,4$ & 4,9 & 4,4 & $-0,6$ & $-2,0$ & 4,2 & 4,4 \\
\hline & C4' & $-10,5$ & $-10,4$ & 5,2 & 4,5 & $-1,1$ & $-2,3$ & 4,0 & 4,7 \\
\hline \multirow[t]{5}{*}{$\overline{A L T}$} & $\overline{F z}$ & $-10,2$ & $-9,9$ & 4,7 & 4,0 & $-1,6$ & $-3,0$ & 3,9 & 5,1 \\
\hline & $\mathrm{Cz}$ & $-10,4$ & $-11,3$ & 6,0 & 4,7 & $-2,1$ & $-2,3$ & $3,6 *$ & $5,4 *$ \\
\hline & $\mathrm{Pz}$ & $-8,8$ & $-9,2$ & 4,7 & 2,4 & $-1,6$ & $-1,4$ & $4,4 *$ & $7,0 *$ \\
\hline & C3' & $-9,2$ & $-9,7$ & 4,2 & 3,7 & $-2,1$ & $-2,6$ & 3,3 & 4,3 \\
\hline & C4' & $-10,0$ & $-10,3$ & 4,6 & 3,3 & $-2,0$ & $-3,0$ & $3,4 *$ & $4,9 *$ \\
\hline \multirow[t]{5}{*}{ BSMT } & $\overline{F z}$ & $-10,3$ & $-10,3$ & 4,1 & 5,0 & $-0,4$ & $-2,1$ & 7,0 & 7,2 \\
\hline & $\mathrm{Cz}$ & $-11,1$ & $-12,0$ & 5,6 & 5,8 & $-0,2$ & $-1,1$ & 7,2 & 7,0 \\
\hline & $\mathrm{Pz}$ & $-9,5$ & $-9,3$ & 4,5 & 3,9 & $-0,6$ & $-0,3$ & 7,2 & 7,4 \\
\hline & C3' & $-9,8$ & $-10,4$ & 4,2 & 4,4 & $-0,8$ & $-1,7$ & 6,0 & 5,6 \\
\hline & $\mathrm{C}^{\prime}$ & $-10,3$ & $-10,9$ & 3,3 & 4,1 & $-1,1$ & $-2,0$ & 6,4 & 6,4 \\
\hline
\end{tabular}

Table 4. Low tone amplitude differences between extraverts and introverts: $+p<0.1$; $* \mathrm{p}<0.05 ; * * \mathrm{p}<0.01$; 
$\mathrm{Pz}(\mathrm{U}=150 \mathrm{p}<0.05)$ and $\mathrm{C} 4{ }^{\prime}(\mathrm{U}=166 \mathrm{p}<0.05)$ for the low (target) tone. The mean amplitudes of the ERP components for the introverts and extraverts are shown on the tables 3 and 4 .

Reaction time:

There was no significant difference between reaction time of the extraverts $(492 \pm 21 \mathrm{~ms}$ responding the low tone and $465 \pm 17 \mathrm{~ms}$ responding the high tone) and introverts (455 $\pm 26 \mathrm{~ms}$ responding the low tone and $423 \pm 24 \mathrm{~ms}$ responding the high tone) in BSMT task and ALT task $(430 \pm 15 \mathrm{~ms}$ for the introverts and $450 \pm 24 \mathrm{~ms}$ for the extraverts). The both groups weren't different concerning the number of mistakes they made: $6 \pm 2$ for the introverts and $8 \pm 2$ for the extraverts.

\section{Discussion:}

Investigations of ERP components allow analysis of different aspects of information processing functions. The present study was carried out to evaluate (by ERP investigations and reaction time) the sensory-motor and cognitive processing in extraverts and introverts and to reveal if this processing depends on task complexity. Four tasks situation was chosen for our investigation to analyze this processing: passive listening series without any task; binary sensory-motor reaction series with answering to two presented stimuli; sensory-motor reaction task, requiring the attention to be directed to one of two presented stimuli and responding to it and tone counting task, requiring mental activity without sensory-motor reactions.

Our data showed significant differences of stimulus information processing between two groups manifested not only in task series but also in passive listening series.

In the passive listening series the extraverts generated larger $\mathrm{N} 1$ amplitude in comparison to the introverts. It is accepted that $\mathrm{N} 1$ amplitude is related not only to physical parameters of the presented stimuli but also to arousal and it is larger with increasing of attention requirements which can modulate the neural generators of N1 [31]. In these series the extraverts displayed lower P2 amplitude and high percentage of them generated P3 amplitude also. These results reveal that extraverts are more susceptible to self-instructed attention and cognitive processing in non cognitive tasks which gives ground to accept that the reason of higher N1 amplitude of extraverts in these series are attention connected processes.

When the task complexity increased the extraverts showed the tendency of N1 amplitude decrease.

The main differences between two groups were N2 latency and amplitude parameters. The extraverts had shorter N2 latencies and larger N2 amplitudes in cognitive task series: counting series, sensory-motor series - an answering to the low tone and binary sensory-motor reaction series. It is known, that the N200 goes negative in response to a deviation in the form or context of a prevailing stimulus [5] and it could be linked with the cognitive processes of stimulus identification and distinction [32]. In this occasion the extraverts deal with the external stimulation as with more novel stimulation. The N2 amplitude is larger when the target is more difficult to discriminate. Consequently, the $\mathrm{N} 2$ may be related to more effort used by extravert to discriminate the target stimuli [33], [12]. Our data revealed that extraverts made faster discrimination of the presented stimuli and for it more activated brain resources were utilized.

The P3 amplitude was larger in extraverts mainly in Pz record in the counting series. The latency and amplitude differences of ERP components decreased with the increasing of task complexity. The possible explanation of these results could be the received data 
[28], which showed that in easier tasks the introverts had lower cortical activity and higher cortical activity in more difficult tasks. The decrease of differences in task series was not due to habituation processes because the most complex task - binary sensorymotor reaction task, in which the parameter differences disappeared, was done in the second, not in the last series.

In conclusion, the data revealed that detected ERP differences between extraverts and introverts depended on the task complexity and there were quantitative differences between two groups during the task performance. The extraverts had higher cortical activity in comparison with introverts in the easiest task conditions - passive listening. The extraverts were more susceptible to self-instruction and cognitive processing in passive conditions.

\section{References:}

1 Eysenck H J (1967). The biological basis of personality. Springfield, IL: Charles C. Thomas.

2 Näätänen $\mathrm{R}$ and Picton $\mathrm{T}$. The $\mathrm{N} 1$ wave of the human electric and magnetic response to sound: a review and an analysis of the component structure. Psychophysiology 1987; 24: 375 \pm 425 .

3 Beagley $\mathrm{H}$ A and Knight J J. Changes in auditory evoked response with intensity. $\mathrm{J}$ Laryngol Otol 1967; 81: 861- 873.

4 Kimberly A . Cote, Tina. M. Epps and Kenneth B . Campbell The role of the spindle in human information processing of high-intensity stimuli during sleep; $\mathrm{J}$. Sleep Res. 2000; 9: 19 \pm 26 .

5 Patel H S and Azzam N P. Characterization of N200 and P300: Selected Studies of the Event-Related Potential, Int. J. Med. Sci 2005; 2(4): 147-154.

6 Duncan-Johnson C C and Donchin E. The P300 component of the event-related brain potential as an index of information processing. Biol Psychol 1982; 14: 1-52.

7 Ahveninen J, Jääskeläinen I P, Kaakkola S, Tiitinen H, Pekkonen E. Aging and cholinergic modulation of the transient magnetic $40-\mathrm{Hz}$ audiroty response. NeuroImage 2002; 15: 153-158.

8 Simson R, Vaughan H G Jr., Ritter W. The scalp topography of potentials associated with missing visual or auditory stimuli. Electroencephalogr Clin Neurophysiol 1976; 40: 33-42.

9 Ritter W, Simson R, Vaughan H G Jr., Macht M. Manipulation of event-related potential manifestations of information processing stages. Science 1982; 218: 909911.

10 McCallum W C, Barrett K, Pocock P V. Late components of auditory event-related potentials to eight equiprobable stimuli in a target detection task. Psychophysiology 1989; 26: 683-694.

11 Anderer P, Saletu B, Saletu-Zyhlarz G, Gruber D, Metka M, Huber J, PascualMarqui R D. Brain regions activated during an auditory discrimination task in insomniac postmenopausal patients before and after hormone replacement therapy: low-resolution brain electromagnetic tomography applied to eventrelated potentials. Neuropsychobiology 2004; 49: 134-153.

12 Näätänen R and Picton TW. N2 and automatic versus controlled processes. Electroencephalogr Clin Neurophysiol. 1986; 38: 169-186.

13 Picton T W, Hillyard S A. Human auditory evoked potentials:II. Effects of attention. Electroencephalography and Clinical Neurophysiology. 1974; 36: 191199. 
14 Picton $\mathrm{T}$ W. The P300 wave of the human event-related potential. J Clin Neurophysio. 1992; 19: 456-479.

15 Donchin E, Coles M G H. Is the P300 component a manifestation of context updating? Behav. Brain Sci. 1988; 11: 357-374.

16 Polich J, Criado J R. Neuropsychology and neuropharmacology of P3a and P3b; International Journal of Psychophysiology. 2006; 60: 172-185.

17 Stelmack R M, Campbell K. Extraversion and auditory sensitivity to high and low frequency, Perceptual \& Motor Skills. 1974; 38: 875-879.

18 Friedman and R. Meares, Cortical Evoked Potentials and Extraversion Psychosomatic Medicine. 1979; Vol. 41, No. 4

19 Doucet C, Stelmack R M. An event-related potential analysis of extraversion and individual differences in cognitive processing speed and response execution. J Pers Soc Psychol 2000; 78: 956-964.

20 Stelmack R M, Michaud-Achorn A. Extraversion, attention, and habituation of the auditory evoked response. J Res Pers 1985; 19: 416-428.

21 Rammsayer T, Stahl J. Extraversion-related differences in response organization: evidence from lateralized readiness potentials. Biol Psychol. 2004; 66(1): 35-49.

22 Doucet C, Stelmack R M. An event-related potential analysis of extraversion and individual differences in cognitive processing speed and response execution. J Pers Soc Psychol. 2000; 78(5): 956-64.

23 Beauducel B B, Leue A. Energetical bases of extraversion: Effort, arousal, EEG, and performance. International Journal of Psychophysiology 2006; 62(2): 212-223.

24 Gurrera R J, Brian F, O’Donnell, Paul G N, Gainski J, McCarley R. The P3 Auditory Event-Related Brain Potential Indexes Major Personality Traits; Biological Psychiatry 2001; 49: 922-929.

25 Polich J, Martin S. P300, cognitive capability, and personality. Person. individ. Diff 1992; 13: 533-543.

26 Cahill J M, Polich J. P300, probability, and introverted/extroverted personality types. Biological Psychology 1992; 33, 23-35.

27 Stenberg, G. Extraversion and the P300 in a visual classification task. Personality and Individual Differences, 1994; 16 (4): 543-560.

28 Fink A, Neubauer A C. Extraversion and cortical activation: Effects of task complexity. Personality and Individual Differences 2004; 36: 333-347.

29 Annett M. Handedness. - In: Divided visual field studies of cerebral organization (Ed. J. G. Beamond). London, Academic Press, 1982.

30 Паспаланов И, Щетински Д. Българска адаптация на личностния въпросник на Х.Айзенк, Психология, 1984, 5.

31 Woldorff M G. Selective listening at fast stimulus rates: so much to here, so little time. Electroencephalogr Clin Neurophysiol Suppl 1995; 44: 32-51.

32 Hoffman J E. Event-related potentials and automatic and controlled processes. In: Rohrbaugh JW, Parasuraman R, and Johnson R Jr, Eds. Event Related Brain Potentials. New York: Oxford University Press. 1990: 145-157.

33 Fitzgerald $\mathrm{P}$ G, Picton $\mathrm{T}$ W. Event-related potentials recorded during the discrimination of improbable stimuli. Biol Psychol 1983; 17: 241-276. 
Appendix

EPQ - Eysenck Personality Questionary

ERP - Event-Related Potentials

PL - Passive Listening

BSMT - Binary Sensory-Motor reaction Task

CLT - Counting the Low Tones

ALT - Answering with the right index finger only to the Low Tones 